\title{
Supply Network Design to Address Sustainable Development Goals: A Case Study of Blockchain Implementation in Thai Fish Industry
}

\begin{abstract}
Sustainable Development Goals (SDGs) present an opportunity for industries to (re)design their supply chains. It is understood that digital technologies like blockchain can be helpful in achieving certain SDGs linked to livelihoods, food security and the environment by identifying issues and implementing interventions in real-time. However, there is limited understanding over data structure requirements for blockchain technology implementation in digitallyenabled food supply chains. Therefore, this research studies the design of blockchain-centric food supply chains that promote SDGs, within the context of the Thai fish industry. This research is inductive as it employed a bottom-up approach to collect data and information, map fish supply chain operations and generate insights. Key findings suggest that data asymmetry exists in supply chains to achieve SDGs. This research presents four design principles and an integrated technology implementation framework, derived from empirical data, for blockchaincentric food supply chains. The research outcome contributes to the supply chain management field and could ultimately impact the resilience of fishery ecosystems and the achievement of SDGs.
\end{abstract}

\section{Keywords}

fish supply networks; blockchain; sustainability; transparency; traceability; supply chain design, SDGs 


\section{Supply Network Design to Address Sustainable Development Goals: A Case Study of Blockchain Implementation in Thai Fish Industry}

\section{Introduction}

Digitalisation in the manufacturing sector unveils the potential to capture Big Data from an end-to-end manufacturing network perspective and drive operational improvements (Tiwari et al., 2018). However, applications that entail the management of huge datasets encounter several challenges that mainly relate to the limited processing capability of incomplete, unstructured and inaccurate data (Choi et al., 2020). To that end, blockchain technology, a decentralised ledger which facilitates transactions of cryptographed data in blocks, has attracted vivid academic and business interest as it enables authentication, auditability, and confidentiality of transmitted data and information (Lin et al., 2018). In a supply chain operations management context, blockchain has a great implementation potential as it can facilitate complex interactions among network stakeholders and administer the issue of data inconsistencies (Min, 2019). Business reports indicate that about $62 \%$ of supply chain executives have engaged with blockchain (Garner, 2018), while the expected business value added by this Industry 4.0 constituent technology is projected to exceed US\$3.1 trillion by 2030 (Furlonger and Valdes, 2017).

A range of fraud vulnerabilities and counterfeiting issues are identified in food supply chains (van Ruth et al., 2018), which motivate promising experimental applications of blockchain technology on the food and agriculture industries (Kshetri, 2018). In particular, the food industry highly appreciates the food safety and transparency benefits emanating from potential implementations of blockchain as the technology enables efficient data capture, management and control (Bumblauskas et al., 2020). However, the extant body of literature is fragmented as the majority of the related research studies myopically focuses on the 
transparency and traceability benefits of blockchain in supply networks rather than specific design interventions that deliver such benefits. The sustainability implications of blockchain pose an emerging topic in the supply chain management research agenda (Saberi et al., 2019), while the sparsity of relevant studies on food chains motivates research in the field (Feng et al., 2020). To a greater extent, Hughes et al. (2019) declared the potential of blockchain to contribute to a range of the United Nations Sustainability Development Goals (SDGs) via articulating a number of research propositions; however, the authors' recommendations were not industry or use case specific. Notably, the authors did not investigate the role of blockchain towards promoting particular SDGs but rather claimed that the blockchain-targeted propositions can be valid in case specific SDGs are realised. Therefore, the lack of studies exploring the role of blockchain in promoting SDGs, especially with an emphasis on the food industry, constitutes an evident gap in the pertinent literature.

Notwithstanding the proclaimed traceability, transparency and sustainability benefits of blockchain in global supply networks (Saberi et al., 2019), the technology has not yet been applied on real-world end-to-end network applications (Dallasega and Sarkis, 2018). The most significant challenge that hinders blockchain implementation for value creation relates to highlevel collaboration requirements (Kittipanya-ngam and Tan, 2020), along with inconsistencies in data structures characterising the distributed data sources (Muzammal et al., 2019). However, unless data elements and their structure integrate across end-to-end networks, the value of information flows that could fuel performance improvements in supply chain operations is not realised (Gavirneni et al., 1999) while the supply chain maturity process stagnates (Trkman et al., 2007).

Blockchain along with Big Data can expedite Industry 4.0 advancements in food value chain management (Zhao et al., 2019, Kayikci, Yasanur, et al. 2020). However, motivated by the evident paucity of studies exploring the usability of blockchain in real-world contexts (Zhao et 
al., 2019), this research argues that blockchain implementation is not understood from the perspective of supply chain (re)design. From an academic perspective, Treiblmaier (2018) provided a framework linking blockchain attributes to the characteristics of four supply chain management-centric theories, but the provided conceptual construct considered blockchain in a broader sense and did not identify data structure requirements as a distinctive blockchain attribute that can foster the technology's implementation. From a technical viewpoint, the sustainable food supply chain literature lacks application frameworks that can contribute to information visibility in data-driven environments (Kamble et al., 2020), while the operability of typical assets and transaction data in blockchain applications (e.g., business documents, images) is disregarded (Kumar et al., 2020). Considering that blockchain technology in sustainable food supply networks is a nascent, yet unexplored, research field with undetermined real-world challenges (Kamble et al., 2019a), this study bridges this gap by attempting to answer the following research question: How can blockchain-centric supply chains be designed and managed in the food industry in order to achieve SDGs?

It is essential to tackle the abovementioned research question to operationalise blockchain technology for delivering sustainable value networks (Capgemini Research Institute, 2018). More specifically, to address the research question, this study focused on empirically derived value chain effectuation by identifying necessary Key Data Elements and via proposing a framework for implementation of blockchain in food supply network designs, particularly focusing on the Thai fish industry. The limited number of relevant research studies provides high-level discussions over the sustainability benefits of blockchain in fisheries supply chain management (Howson, 2020), without observing data-related implementation aspects of the technology at an operational level. Therefore, to tackle the research question, this study further developed four principles for blockchain-centric food supply chain designs to contribute to SDGs. 
The research emphasis on the seafood industry was stimulated by a range of reasons, including (Gopi et al., 2019): (i) global increasing demand on seafood; (ii) essential nutritional role of fish to human diets; (iii) significance of the seafood market to national economies and global trade; and (iv) increasing global concerns over fish provenance and authenticity, mainly in terms of food safety, quality and fraud. In particular, sustainable fisheries management in Thailand is crucial owing to the significance of the seafood sector to the national economy. Based on the National Food Institute, Thailand is the leading global producer and exporter of canned tuna with a market share of about $40 \%$ (Kittipanya-ngam and Tan, 2020). However, the Thai fish industry encounters major sustainability challenges including illegal fishing activities amounting to financial losses of about US\$5 billion (Wipatayotin, 2019), and unethical labour practices (Sasipornkarn, 2019). Therefore, Thailand's food supply chains need to continuously demonstrate efficiency and sustainability to maintain the leadership position in global exports.

This research followed a multiple case study approach, involving data and information collection from both interviews with stakeholders and field observations, to answer the enunciated research query. More specifically, three case studies were conducted within the context of the Thai fish industry via leveraging three data and information collection mechanisms - semi-structured interviews, field observations, official documentation of supply chain operations - to identify data sources, ensure data validity and generate insights (McCutcheon and Meredith, 1993). The paradigm of the Thai fish industry aligns with the SDGs and helps link blockchain implementation requirements to supply chain design. To the best of our knowledge, no peer-reviewed research article on blockchain technology in end-toend fish supply chains has combined literature analysis and empirical evidence.

Our research contributes to the Operations Management field by applying a multiple case study approach to develop a pragmatic view over traceability in fish supply chains enabled 
by blockchain technology. In addition, this research studies the relationship between blockchain technology and supply chain design within the prospect of product traceability.

The remainder of this research is structured as follows. Section 2 summarises indicative studies examining blockchain in the food industry and provides the research background over blockchain implementation and supply chain design. Section 3 details the research methodology applied to gather and analyse evidence on the application of blockchain technology in the fish industry. Section 4 investigates the fishery ecosystem in Thailand. An integrated framework capturing supply chain (re)design implications stemming from the implementation of blockchain technology is proposed in Section 5. Critical evaluation of the research findings along with academic and management implications, limitations and future research avenues are explored in the final Section 6.

\section{Research Background}

Key studies discussing blockchain in end-to-end food supply networks were reviewed followed by an investigation of pertinent extant works focusing on the seafood industry and on sustainability implications. Additionally, major literature evidence on the design of technology-enabled supply networks was retrieved.

\subsection{Blockchain in Food Supply Networks}

Blockchain technology's expected benefits are clearly documented for the food industry, mainly referring to advanced traceability capabilities and increased food safety leading to enhanced consumers' trust. In addition, blockchain could help mitigate the ripple effect that describes the propagation of any risks downstream a food supply chain, hence further impacting a network's structural design and planning parameters (Dolgui et al., 2018). 
Key studies investigating the potential application and implementation of blockchain within a food supply network context were recognised and taxonomised. An exhaustive review of all research works in the field extends the scope of this research. Most recently published review articles on the topic indicatively include the studies of Antonucci et al. (2019), Kamble et al. (2020) and Lezoche et al. (2020).

\subsubsection{End-to-end food chains}

Crew (2018a;b) discussed the role of blockchain in enhancing consumers' trust and food safety as the technology enables transparency, tracking and traceability in transactions among endto-end food supply network stakeholders. Notwithstanding the conceptual discussions in the domain, the need for feasible food traceability systems led Behnke and Janssen (2020) to investigate four dairy supply chain processes and identify five boundary conditions (recognised across the business, quality and traceability categories) for the implementation of blockchain technology. In a similar vein, Chen et al. (2020) performed a thematic analysis of news articles and research studies jointly discussing blockchain and food networks, and they identified processes, benefits and challenges prevalent in the adoption of the technology in food supply chains.

Furthermore, Kim and Laskowski (2018) developed a proof-of-concept ontology-based blockchain and investigated the feasibility of a traceability ontology for food supply chain provenance. Marfia and Degli Esposti (2017) considered blockchain for the case of organic farming to guarantee trust and increase product value. Similarly, Mondal et al. (2019) implemented a blockchain architecture enabled by a Radio-Frequency Identification (RFID) sensor to develop a tamper-proof digital database of food packages.

Sander et al. (2018) surveyed the perceptions of meat supply chain stakeholders about blockchain, as a viable meat transparency and traceability system, and concluded that the 
technology could positively influence consumers' purchasing decisions in case trust towards blockchain is established. In cold food supply chains, blockchain is appreciated as the technology can promote transparency over temperature information about food products, particularly during storage and distribution, thus fostering waste mitigation (Ndraha et al., 2018). Additionally, Tian (2017) conceptually investigated the architecture of a food supply chain traceability system enabled by HACCP (Hazard Analysis and Critical Control Points), blockchain and Internet of Things, as a solution to support food safety and consumers' trust in the industry.

On a more pragmatic basis, Kamilaris et al. (2019) reviewed ongoing initiatives and projects on blockchain technology in agriculture and food supply networks, and further discussed related implications, benefits and challenges. Indicatively, Walmart leads an initiative along with Nestlé SA, Unilever NV and other global companies to develop the Food Trust blockchain with the aim to trace and manage potential risks across end-to-end food supply chains (Nash, 2018). Likewise, Pendrous (2017) discussed trends and business initiatives (e.g., the joint initiative by Arc-net and $\mathrm{PwC}$ Netherlands) regarding the development of a blockchain-based platform across food supply networks to deliver product safety, quality and integrity.

\subsubsection{Seafood industry}

From a seafood supply chain operational perspective, Cook (2018) reported the benefits and challenges of a related pilot project on blockchain implementation, led by the World Wide Fund for Nature (WWF), particularly focusing on tuna caught in a Fijian longline fishery. Furthermore, Intel applied its proprietary open source blockchain platform, named Hyperledger Sawtooth, to enable seafood traceability and ensure compliance with storage conditions across fish supply chains (del Castello, 2017). Fishcoin, a blockchain-based data ecosystem dedicated 
to the seafood industry, utilises tokens for incentivising data capture and transmission across fish supply chains in order to increase traceability (Fishcoin, 2018).

In addition, the social enterprise Project Provenance Ltd tested a prototype blockchain model to track and trace responsibly caught tuna fish in Indonesia by gathering diversified data across operations, from vessel tracking and registration to self-reporting of fish catch and fish tagging (Provenance, 2016). Moreover, WWF piloted the use of blockchain technology in the Pacific tuna industry to trace fish provenance, track illegal fishing instances and eliminate abuses of human rights (WWF, 2018). Visser and Hanich (2018) discussed the transparency and traceability benefits of blockchain in aforementioned real-world pilot implementations, further highlighting the technology's contribution in tackling poor human working conditions in low-income countries. From a fish supply chain management perspective, Mathisen (2018) investigated the strategic compliance of blockchain technology to Norwegian aquaculture producers and discussed potential benefits with regard to the expected efficiency in terms of quality, cost, sustainability and dependability.

\subsubsection{Sustainability}

In terms of sustainability, Ahmed and Broek (2017) summarised the potential food security benefits stemming from the adoption of blockchain technology in food supply networks, particularly stressing the emanating possibilities of distributing surplus food supplies to beneficiary bodies and enhancing the visibility over the environmental footprint of commodities/products. Chapron (2017) critically discussed governance and sustainability benefits stemming from the implementation of blockchain technology in manufacturing and food supply chain operations and particularly highlighted the associated potential of natural resources stewardship along with social sustainability implications. Moreover, Lin et al. (2017) 
discussed the evolutionary role of blockchain in agriculture to enable efficient water quality monitoring in farms.

In a humanitarian context, Juskalian (2018) presented the case of the "Building Blocks" initiative, set by the World Food Programme of the United Nations, which uses blockchain technology and iris scanning technology to allow refugees in Jordan to purchase daily grocery supplies. The author also discussed the efficiency gains deriving from the adoption of blockchain for humanitarian operations, including: (i) reduced bank fees applicable to transfers of humanitarian aid funds; (ii) digital proof of refugees' identity and educational/employment history that increases employment opportunities in hosting countries; and (iii) enhanced efficiency in humanitarian aid operations of international organisations.

\subsubsection{Critical taxonomy}

A critical taxonomy of the reviewed literature on blockchain technology in food supply chains is presented in Table 1. The taxonomy reveals that most of the studies published in peerreviewed scientific journals are limited on a discussion of potential benefits and challenges related to the adoption of blockchain technology in food supply networks. Few studies, basically retrieved from grey literature, focus on real-world implementation cases while no articles highlight the role of data structures and supply chain (re)design opportunities. The general consensus is that blockchain technology can mainly ensure transparency and traceability in food systems with further positive effects regarding food safety and consumers' trust.

[Table 1 about here]

Table 1. Blockchain technology in food supply networks: An overview. 


\subsection{Technology-enabled Supply Network Design}

Blockchain is recognised as an ordered list of blocks that contain data and information regarding transactions, records and events (Kamble et al., 2019b). However, the structure of the gathered and transmitted data along with the need to (re)design prospective blockchainenabled supply networks are often being neglected in the extant literature.

\subsubsection{Data and supply chain design ramifications}

Sener et al. (2019) found that information usage, rather than information sharing, among supply chain stakeholders could result in significantly better performance in terms of inventory, transportation, warehousing, and communication related costs. In tandem with the tamper proof records of blockchain that help cultivate a culture of trust, the commercially viable nature of end-to-end supply networks could be ensured (Nidumolu et al., 2014). Within a digitalised business environment, we adopt the suggestion of Kohtamäki et al. (2019) who recognised that data alignment among firms within specific ecosystems can propel value capture by all involved stakeholders. To that end, supply chain processes need to be (re)designed to accommodate blockchain-related data requirements and specifications.

\subsubsection{Blockchain implementation elements}

Astill et al. (2019) identified key technological enablers required to advance transparency in food supply chains, namely: (i) data acquisition technologies; (ii) Internet of Things; (iii) data management platforms; and (iv) big data analytics solutions. Furthermore, dos Santos et al. (2019) described the implementation of smart contracts and blockchain tokens, based on the ISO 22005:2007 standard, to certify the origin of food ingredients via a mobile phone application. Also, Borrero (2019) provided an overview of blockchain implementation in the supply chain of berries in southern Spain and highlighted basic technical requirements. 
Kumar et al. (2019) examined blockchain design and implementation phases in a food supply chain context with the aim to provide a pragmatic view about the associated key challenges of storage, networking and processing costs. Moreover, Kamble et al. (2019b) identified thirteen enablers of blockchain technology in agriculture supply chains and further investigated the underpinning causal relationships. Table 2 summarises blockchain implementation elements in supply networks and further depicts the particular lack of focus in the structure of the data needed to be collected from different echelons of operations.

[Table 2 about here]

Table 2. Blockchain implementation elements in supply networks.

\section{Materials and Methods}

Considering that the outcome of this research shall contribute to SDGs through developing principles for blockchain-centric supply chain design, along with a technology implementation framework, the object of scrutiny has to be a critical analysis of the relevant literature (Tranfield et al., 2003), whilst further supported by real-world case studies (Gibbert et al., 2008). Therefore, following the provided literature overview in the field, the theoretical lens and the research design underpinning this study are detailed in the sub-sections that follow.

\subsection{Theoretical Lens}

The realisation of food traceability is not underpinned by any generally approved conceptual framework or theory (Karlsen et al., 2013). To that end, motivated by the need to support realworld blockchain implementation in fish supply network operations, this study followed a pragmatist research philosophy to allow the collection of both objective and subjective data (Saunders et al., 2009). 
From a theoretical standpoint, the enabling role of blockchain technology in fulfilling supply chain management objectives (e.g., cost, quality, flexibility) has been recognised (Ksherti, 2018). However, to systematically investigate blockchain in the supply chain management arena, we complementarily adopted the "Principal-Agent Theory" and the "Transaction Cost Theory" for blockchain-centric supply chain (re)design, along with the "Resource-Based View" and the "Network Theory" for blockchain-centric supply chain management (Halldórsson et al., 2007). A combination of these theories has been applied to motivate middle-range theory development for interpreting structural and management changes in supply chains imposed by disruptive technologies (Treiblmaier, 2018).

Following the theoretical framework of Halldórsson et al. (2007), and considering that data structure was not distinctly contemplated by Treiblmaier (2018), this research selected blockchain data as the primary focus of analysis. In particular:

- "Principal-Agent Theory" - Information asymmetry between supply and demand echelons is a common issue in supply chain management that can negatively impact stakeholder relationship (Whipple and Roh, 2010). Therefore it can be argued that consistent data structures enable blockchain technology implementation and are a requisite to align priorities and inter-firm contracting perspectives (Jensen and Meckling, 1976).

- "Transaction Cost Analysis" Theory - Data visibility and reliability are key in governing production and transaction costs in a supply chain owing to the higher level of information sharing that helps assess performance of contractual agreements and reduce opportunistic behaviour (Wacker et al., 2016). Therefore, based on the "Transaction Cost Analysis" Theory, asset specificity from the angle of data capture is a key attribute of supply chain transactions enabled by blockchain technology (Rindfleisch and Heide, 1997). 
- "Resource-Based View" Theory - Accurate data is recognised as a primary resource for supply chain operational performance and competitive advantage (Chae et al., 2014). However, data can be found in varied types within a supply chain that may lead data usability in a specific analytical system or software. In particular, the understanding of the stratification and identification of existing data types could help tackle triple bottom-line sustainability concerns (Raut et al., 2019), like food losses and waste generation (Irani et al., 2018). To that effect, following the "Resource-Based View" Theory, data interoperability even at the level of insignificant processes can assist in the heterogeneity of supply chain data sources and capabilities, and to the configuration of operational competency (Halldórsson and Skjøtt-Larsen, 2004).

- "Network Theory" - Except for transactions in supply chains, data is a driver of interorganisational relationships and can be used to establish interfaces among the different types of resources at the involved operational echelons (Rinehart et al., 2004). Consequently, in accordance to the "Network Theory", streamlining data archetypes among the various dispersed data sets is essential for assuring two types of stakeholder interactions (Johanson and Mattsson, 1987): (i) exchange processes (e.g., information, products); and (ii) adaptation processes (e.g., legal, administrative elements).

Therefore, this research investigated the unexplored linkages between the unit of analysis per considered complementary theory to understand supply chain (re)design and management opportunities enabled by blockchain technology (Figure 1). Specifically, we argue that supply chain (re)design should include the elements of data consistency and data capture to eliminate any transaction errors that can impact operational and sustainability performance assessment, along with the pertinent decision-making process. Indicatively, ensuring data unit consistency across-end-to-end supply chain operations and the utilisation of technologies to capture data can help eliminate human errors. Furthermore, to manage 
blockchain and the available multiple types of data in sustainable supply networks, SDGcentric data interoperability and archetypes are required. Traditional data interoperability and archetypes typically have a financial focus and may not capture sustainable development perspectives.

[Figure 1 about here]

Figure 1. Data-centric research model for supply chain design and management enabled by blockchain technology.

\subsection{Research Design}

Considering that the aim of this research is to derive theoretical findings with practical implementation potential, a multiple case study research strategy was adopted (Yin, 2003). The case study approach allowed to combine a range of data and information gathering methods, like interviews and field observations, thus fostering the understanding of the real-world context of blockchain-enabled food supply chains (Eisenhardt, 1989). This research is inductive as it employed a bottom-up approach to collect data and information, map fish supply chain operations and generate insights.

\subsubsection{Case identification}

Aquaculture constitutes an important source of national incomes, specifically for developing countries; hence, blockchain could catalyse seafood trade and logistics by establishing direct links between producers and consumers (Bush et al., 2019). Indicatively, Thailand is a major global seafood trader with exports valued at US\$5.8 billion in 2017 , contributing about $20 \%$ to the national food exports (USDA, 2018). However, the limited application of efficient and reliable traceability systems across end-to-end fish supply chains often results in significant 
marine fishery resources overexploitation, product recalls, foodborne illnesses, and financial losses (Xiong et al., 2016). For example, overfishing phenomena exert significant pressure on the marine fisheries' stock in the Andaman Sea and the Gulf of Thailand. Notably, the European Commission asserted pressure on Thailand to proceed to timely improvements on the governance of illegal, unreported and unregulated fishing activities by issuing the country with a yellow card (European Commission, 2015). In this regard, implementing a reliable fullchain traceability system in the Thai fishery ecosystem could improve the export outlook of the sector.

The main SDG challenges related to the Thai fish industry are inserted in Table 3. To develop a more robust construct about blockchain in the Thai fishery ecosystem, we conducted three case studies to collect essential data, namely: (i) Case study \#1 - Local fishing operations; (ii) Case study \#2 - Commercial fishing operations and trade; and (iii) Case study \#3 - Canned tuna manufacturing. The different scale of operations investigated through these case studies allowed the identification of particularities and the investigation of blockchain implementation challenges and potential in the Thai fishery ecosystem, hence assisting in generating robust and valid results.

[Table 3 about here]

Table 3. Blockchain in the Thai fish industry and relevant United Nations Sustainable Development Goal challenges.

\subsubsection{Data collection}

The approached Thai fish supply chain stakeholders were initially involved in semi-structured interviews and field research; the interview participants represent the main stakeholders in the Thai fishery ecosystem hence allowing the collection of data and information from different 
perspectives and over a range of processes, technical aspects, social angles and legal related issues. In particular, seven key categories of actors were recognised involving a total of fifteen informants, namely: (i) fishermen; (ii) traders; (iii) processors; (iv) wholesalers; (v) technology providers; (vi) certification organisations; and (vii) governmental bodies.

Especially, data and information were collected via three case studies involving: (i) thirteen semi-structured interviews with stakeholders in the Thai fish industry; (ii) three physical walkthroughs; and (iii) official documentation used during the operations. Table 4 enlists the interviews' informants along with the selection criteria and the utilised data collection methodology. Table A1 in the Appendix summarises the salient points of the interviews. The triangulation of data captured via direct field observations and documentation of operations assisted in mitigating the bias from the semi-structured interviews to ensure validity and quality of findings (Yin, 2009).

[Table 4 about here]

Table 4. Interviews' informants, selection criteria and data collection mechanism.

\subsubsection{Data analysis}

The data and information collected were analysed based on the principles adopted from the Best Practice Guidelines on Traceability (FAO, 2014), as summarised in Figure 2. Initially, TraceFish (i.e. a series of voluntary standards relating to information recorded at every fish supply chain stage) was used to evaluate the completeness of data collection by different supply chain stakeholders as being the acceptable standard in the industry (Konovalenko and Ludwig, 2019). The data collected from the case studies was compared to the list of Key Data Elements recommended by TraceFish to determine the completeness of stakeholders' data sets. Secondly, the "Unique Identification" (i.e. any unit or actor that modifies the product should 
be recognisable) was assessed by using a process mapping framework for seafood firms' traceability systems developed by Mai, Margeirsson et al. (2010). Thirdly, data sharing was evaluated by analysing the communication method between various stakeholders and vertical integration. Finally, the capabilities of the technology were analysed against a set of criteria gathered from literature and the case studies.

[Figure 2 about here]

Figure 2. Fish supply chain analysis framework based on the Best Practice Guidelines on Traceability.

\section{Fish Supply Network Ecosystem in Thailand}

The fishery ecosystem in Thailand consists of thirteen distinct actors, as these are mapped on three clusters (Figure 3), namely: (i) national bodies; (ii) key stakeholders; and (iii) certification bodies. Notably, every national entity utilises its proprietary database despite any overlaps over the gathered data. Therefore, an increased probability of maintaining duplicate datasets and incomplete databases exists.

[Figure 3 about here]

Figure 3. Key actors in the fish supply network ecosystem in Thailand.

From a legislative perspective, fishing is only allowed to registered vessels. Officially, two types of vessels are recognised in Thailand (Table 5): (i) local fishing vessels; and (ii) commercial vessels. Local fishing vessels are neither required to install a Global Positioning System tracker nor to have a logbook. On the other end, commercial vessels are required to have installed a Global Positioning System tracker, called Vessel Monitoring System, to inform 
about the real-time location of the vessel and to record all required information onto an issued logbook. Currently, a total of 27,261 registered local vessels and 10,615 registered commercial vessels operate in Thailand.

[Table 5 about here]

Table 5. Major Thai fishery legislative requirements by vessel size (Source: Department of Fishery, 2018).

\subsection{Case Study \#1 - Local Fishing Operations}

In order to map local fishing operations, the activities of "Fishermen 1", who own a 9 Gt vessel in Prachuap Kiri Khan, were observed. The laws applicable to local fishermen are loose and this reflects upon the management style of "Fishermen 1".

\subsubsection{Fishing processes}

At the predeparture stage, "Fishermen 1" load ice and insulation storage boxes on the vessels while the fishing equipment is prepared the previous day (see Image S1 in the Supplementary Material). Regarding the fishing method, "Fishermen 1" use the 'purse seining' approach which allows the capturing of targeted fish species with a low probability of unintentional bycatches. The final captured fish are sorted by size and stored inside boxes/buckets of ice (see Image S2 in the Supplementary Material). After the fishing is completed, "Fishermen 1" return to the port to unload the catch and trade with fishmongers.

"Fishermen 1" return to the departed port, without having to comply to a particular schedule or inform any authority, unload and weight the fish catch. The empirical study revealed that approximately $3 \%$ of the catch would be characterised by minor damages such as bruises; however, these fish are not discarded as such defects are considered insignificant. 
Thereafter, fishmongers would sell the fishes to the local market. The market usually consists of local restaurants and consumers. The process flow diagram of "Fishermen 1", resulting from observations and interview insights, is illustrated in Figure 4.

[Figure 4 about here]

Figure 4. Local fishing operations process flow diagram.

\subsubsection{Data captured}

Considering the legislative requirements for vessels with size less than $10 \mathrm{Gt}$, "Fishermen 1" are not obliged to gather any data related to fishing operations and to the fish catch per se. The only recorded information refers to the invoices of fishmongers which state the weight, species and price of the traded fish.

\subsection{Case Study \#2 - Commercial Fishing Operations and Trade}

Commercial fishing operations are performed by "Fishermen 2" who are located in Phuket. The entire process is more complicated compared to local fishing operations owing to the dominant interdependency among storage duration, fish freshness and profit which could affect the scheduling of the operations and the quality of the traded seafood.

\subsubsection{Fishing processes}

"Fishermen 2" empirically prepare sufficient volumes of ice for storing and preserving seafood during fishing to achieve maximum profit under the constraints of seafood freshness and vessel's fuel. Fishing vessels cannot be sailing for more than thirty consecutive days; nevertheless, "Fishermen 2" return to port within about fifteen days of departure to maintain the freshness of the caught fish. Every vessel is equipped with a Vessel Monitoring System 
that tracks and monitors the fishing operations while the data are centrally stored and managed by the Department of Fisheries to inspect for any illegal, unreported and unregulated activities. "Fishermen 2" use the 'fishing trawler' method which is considered unsustainable as it associates to high killing rates of by-catches. In this regard, any endangered fish species caught are required to be recorded on the vessel's logbook (see Image S3 in the Supplementary Material). The trawling process is performed three to four times during a day. Thereafter, the catch is released onto the vessel and the sorting process begins while the trapping is repeated (see Image S4 in the Supplementary Material).

In Thailand there are thirty ports that can accept commercial vessels for unloading seafood to prevent unreported catch. In this regard, fishermen are required to book a date and request a specific time-window from the destination port to land vessels and unload the catch. In addition, a 'Port-In-Port-Out' form must be administered to the Department of Fisheries while a photographic copy of the logbook data for the trip must be submitted via a public messaging application to obtain approval prior to unloading the catch at a specified port (see Image S5 in the Supplementary Material). "Fishermen 2" then unload and deliver the catch to the trader. Notably, the fish storage containers include a varying amount of ice due to lack of storage conditions monitoring or differences in the dates of the catch (see Image S6 in the Supplementary Material). The process flow diagram of "Fishermen 2" is depicted in Figure 5.

[Figure 5 about here]

Figure 5. Commercial fishing operations process flow diagram.

\subsubsection{Trading processes}

Traders are responsible for supplying the consumers' market with seafood delivered by the fishermen, with the risk of unsold units. A trader proceeds to a more accurate seafood sorting 
process performed on an aluminium platform (see Image S7 in the Supplementary Material). The seafood is segregated into different containers according to species, size, freshness and appearance while it is not preserved in ice until the end of the auction. Each sorting container is labelled by the fishermen with a printed vessel code (see Image S8 in the Supplementary Material) to account for traceability (see Image S9 in the Supplementary Material). Following the seafood weighting and provision to the market (see Image S10 and Image S11 in the Supplementary Material), the gathered data (already recorded in the vessels' logbook) are reported to the 'Port-In-Port-Out' form by the traders to prevent overfishing and illegal trade. The process flow diagram of the "Trader" is shown in Figure 6.

[Figure 6 about here]

Figure 6. Seafood trading process flow diagram.

\subsubsection{Data captured}

Every stakeholder involved in commercial fishing activities needs to record data. "Fishermen 2" are required to record all their data on the fishing logbook while, prior to unloading the catch, a 'Port-In-Port-Out' form must be completed. Traders need to record less data compared to fishermen. Data required for international customers, where international standards apply, would be different. The detailed list of Key Data Elements recorded in commercial fishing operations is inserted in Table A2 in the Appendix.

\subsection{Case Study \#3 - Canned Tuna Manufacturing}

The approached canned tuna processor is located in the Hat-Yai city and produces personalised fish product labels according to customer specifications. In 2017, the manufacturer received 45 million $\mathrm{kg}$ of tuna, $80 \%$ of which was imported. 


\subsubsection{Canned tuna processes}

In terms of inbound logistics, tuna is delivered in containers which would then be loaded onto a conveyor so that fish are manually sorted by weight. To conduct quality control tests, a random sample is taken from the batch. Following the inspection and sorting process, the batch is registered to the inventory system and transferred to the cold storage warehouse with a maximum storage duration of three months.

Regarding the manufacturing process, tuna would be taken out for the thawing process and would be traced with the use of a production card as a method for tracing material flows (see Image S12 in the Supplementary Material). After the cleaning, tunas are placed on trolleys where relevant information would be recorded on the production card. Herein, all data are recorded by RFID tags (see Image S13 in the Supplementary Material) which accompany the tuna until the end of the filleting process. The fillets are then automatically canned. The ingredients and packaging identification number would be linked to the product identification number for traceability purposes.

Production output is affected by three main factors, namely: (i) tuna size; (ii) tuna species; and (iii) skills of operators. The process flow diagram of the canned tuna manufacturing activities is illustrated in Figure 7.

[Figure 7 about here]

Figure 7. Canned tuna manufacturing process flow diagram.

\subsubsection{Data captured}

Data required to be captured by the canned tuna manufacturer depends on the specifications of the customers. After the tunas are being weighted and sorted, the traceability information 
provided by the supplier for the production batch would be linked to each batch's identification number. A final sealing report for each batch would be created and approved by the quality control department. The comprehensive list of Key Data Elements for the canned tuna manufacturing supply chain is provided in Table A3 in the Appendix.

\section{Discussion}

Evidence derived from the literature and empirical observations reveal that notwithstanding the proliferation of industrial discussions and academic studies on blockchain, limited understanding is demonstrated over the data structure requirements for supporting the technology implementation and the respective supply chain (re)design. The results of the case studies suggest that data consistency, capture, interoperability and archetypes-related issues exist in the Thai fish supply chain that could ultimately impact the resilience of the fishery system and the achievement of SDGs. To that end, this research articulates four principles for blockchain implementation, namely:

- Principle \#1 "Data Archetypes" - Linking data sets available in multiple echelons of supply chains is essential.

- Principle \#2 "Data Capture" - Data on technology limitations needs to be captured.

- Principle \#3 “Data Consistency" - Data archetypes should not only be developed for compliance purposes, but they have to extend beyond regulatory requirements.

- Principle \#4 "Data Interoperability" - Insignificant supply chain processes and operations have to be accounted.

\subsection{Data Archetypes (Principle \#1)}

The observations of fishermen, traders and the manufacturer's activities emphasise the lack of interface between operations and information flow, in terms of workflows and data triggers, 
meaning that the granularity of data is lost at the transition points from upstream to downstream supply chain operations thus limiting transparency and traceability. Key observations with regard to the limited possibility of linking data across fish supply chains include:

- Legislative voids - Fish supply network stakeholders might leverage legislation to avoid recording data that could reassure traceability and food safety. For example, local fishermen are not obliged to record any data. However, considering the local fishing capacity ( $\sim 72 \%$ of total vessels) and the short cycle-times of the respective operations, fishmongers have access to fish supplies that are only accounted for their weight and species. The absence of any records also allows the possibility for overfishing and bycatches of endangered species. In addition, commercial fishermen and traders are not required to record any data with regard to fish unloading, sorting and storage conditions.

- Not standardised data structure and recording format - The lack of standardisation in data structures and means of data recording establishes decoupling points across supply chain transactions. Firstly, local fishermen do not need to record any data and fishmongers have visibility only about the species and the weight of the traded fish supplies. Secondly, commercial vessels use a manually-updated logbook to record data with regard to the fishing activities while the Vessel Monitoring System is used only for verifying the location of vessels and not to record or transmit fish catch reports. Furthermore, the arrival ports require only a pictorial copy of the logbook, a format that does not allow the automatic extraction and analysis of the data gathered during fishing activities. Thereafter, traders sort the fish into containers and the only traceability element refers to a hand-written note with each vessel's code. Thirdly, the canned tuna manufacturer receives fish containers without maintaining data on the geographical origin of the fish. Quality inspections on the production line are based on random samplings without providing the capability to track the vessel of origin or even the 
trapping process.

Therefore, linking data sets available across the different supply chain echelons of operations is essential to ensure sustainable performance. Adopting common data archetypes can assist towards this direction.

\subsection{Data Capture (Principle \#2)}

Data capture mechanisms and technologies have inherent technical limitations and functional challenges that raise data reliability concerns. On the one end, paper-based data recording on logbooks entails bias, lacks accuracy, enables duplicated data recordings and renders the data not reliable or even not accessible in case the physical logbook is damaged. On the other end, functional disruption of the data recording mechanisms could result in data inconsistencies or gaps. Indicatively, during commercial fishing operations the intentional or unintentional malfunction of the Vessel Monitoring System could result in the manipulation of the fishing location data thus raising visibility concerns over illegal fishing operations.

Another technical aspect refers to the calibration of any used equipment. For example, the mere common metric used to assess the traded seafood is the fish weight; however, the weighting process is typically executed by using a probably decalibrated or malfunctioning equipment. In addition, quality controls, if any applied in practise, are based on visual inspection that entails the subjective judgement of the involved stakeholders. Therefore, capturing data with regard to technology limitations is essential to allow for data accountability and trust.

\subsection{Data Consistency (Principle \#3)}

Empirical evidence led to the conclusion that data regarding the flow of food products throughout the supply network is only recorded for merely regulatory compliance purposes and 
is not leveraged to essentially support fish traceability or to inform downstream operations.

In a future state, to realise the potential of advanced traceability systems, data collection accountability would require stakeholders to demonstrate relevant responsibility. For example, local fishermen account for about $70 \%$ of the total fishing vessels and are not required to install a Vessel Monitoring System. Therefore, adulteration, commercial frauds and dangerous substitutions are possible, whereas in case of quality and safety incidents food recalls of particular fish batches will not be feasible. Moreover, the reporting of by-catches of endangered species is manual, thus the monitoring of any environmentally or wildlife biodiversity damaging actions is not ascertained. To that end, data consistency is needed as data archetypes should not only be developed for compliance purposes, but they have to extend beyond regulatory requirements.

\subsection{Data Interoperability (Principle \#4)}

The scope of traceability needs to guide the design of data collection and sharing. For the case of the Thai fish industry, the primary aim of data recording is to avoid illegal, unregulated and unreported fishing operations. However, this is contradictory to the fact that around $70 \%$ of the fishing vessels are not required to be equipped with an electronic positioning system. In addition, certain critical operations are overlooked in terms of data monitoring, including:

- Ice preparation - The volume and condition of the ice prepared prior to fishing activities is not monitored. The temperature of the ice is not recorded while the ice might not ensure the appropriate preservation conditions for the stored fish after the catch. Similar reasoning applies for the ice used to store fish in containers for trading.

- Fish unloading - The unloading of the fish occurs on the vessel's deck or on aluminium platforms at the port. The cleaning process of these surfaces, if any exists, is not documented. 
- Fish sorting - The sorting of fish, occurring either on a vessel's deck or at the port, is prone to subjectivity errors particularly in terms of species and skin quality.

In this regard, data interoperability is important as multiple insignificant supply chain operations are often being overlooked; however, the aggregate effect of such neglected processes could severely impact the sustainability of fish supply network operations.

\subsection{Blockchain-centric Supply Networks Design and Implementation Framework}

Main concerns relating to fish supply chain operations include: (i) lack of connectivity between different departmental databases; (ii) no logbook requirement for local fishing vessels; (iii) lack of requirement for Vessel Monitoring System installation on local fishing vessels; (iv) inability to share logbook information in real-time; (v) $20 \%$ tolerance allowance on the accuracy of the amount of fish catch; and (vi) unregistered vessels. To that end, blockchain could consist a feasible technology intervention for the viability and sustainability of the fishery ecosystem in Thailand but requires a set of supply chain design and technology implementation decisions.

\subsubsection{Research findings}

Lack of databases' integrity in the Thai government system instigates data inaccuracy issues in the fish industry like incorrect number of registered vessels, thus overlooking illegal activities and impeding traceability. As local fishing vessels are triple in number compared to commercial vessels, about 11-26 million tons of fish caught annually are not recorded and are not considered in the sustainability assessment of the national aquaculture ecosystem. In addition, due to the technical inability for real-time sharing of the vessels' logbook information, a tolerance level of $20 \%$ is allowed on the accuracy of the amount of the fish catch. Considering 
the nature of the challenges in the Thai fishing industry, Table 6 summarises main blockchaincentric supply chain design recommendations for the seafood industry.

\section{[Table 6 about here]}

Table 6. Blockchain-centric supply chain design recommendations for the seafood industry.

\subsubsection{Blockchain implementation framework}

Blockchain applications in the food sector provide added value in areas like trust, security and decentralisation (Galvez et al., 2018). However, extant studies focus on the business benefits or information technology elements of traceability systems without discussing the data structures and their importance to supply chain management. Our claim is that the design of blockchain-centric supply chains should first consider the existing data structures and technology specifications in place. To that effect, the adoption process of an effective blockchain platform includes decisions at both supply chain design and technology implementation levels, as depicted in the proposed framework in Figure 8.

[Figure 8 about here]

Figure 8. Integrated framework of blockchain-centric supply chain design and technology implement.

\subsubsection{Design decisions}

Transitioning towards value networks enabled by blockchain technology requires that fundamental traceability systems are implemented to achieve tangible (e.g., market growth) and intangible (e.g., corporate reputation) benefits (Mai, Bogason et al., 2010). In this regard, an effective production identification system has to already link resources to other Key Data 
Elements and to the finished product. Following that, on the condition that Key Data Elements are complete, the data gathering method is important for ensuring data accuracy. A blockchain database is a trusted database in an untrusted environment. In this sense, blockchain could be complemented by Internet of Things technologies to increase productivity and food traceability (Tian, 2017). Automation (e.g., RFID e-tagging and scanning of fish) ensures data accuracy as it eliminates human errors and intentional fraud that typically result in incorrect information (Girard and Du Payrat, 2017). The use of sensors and automation allows the integration of total quality management in the blockchain. Basic digital technologies that need to underpin blockchain include:

- RFID tags to trace fish from origin and collect data transmitted directly from sensors (e.g., date, time, temperature).

- Smart weighting system that takes into consideration a vessel's movement while weighting the fish catch during fishing operations. Weight logging could be automated to help forecast the landing date to the selected port.

- On-board survey cameras and electronic monitoring systems to help identify interactions with by-catches and protected species.

The benefits of blockchain in end-to-end supply networks can be operationalised through the establishment of a trustworthy traceability system that enables sharing of critical data among all collaborating actors. For instance, upstream suppliers would benefit from improved relationships with corporate customers to generate more business opportunities while downstream customers gain access to trusted data that prevent fraud and ensure food safety. Collaboration is recommended both among companies to improve the audit process and between governmental authorities of neighbouring countries to improve accuracy in aquaculture monitoring and fishing operations. 
Furthermore, a major design decision is to select the on-chain or off-chain attributes to be shared on a blockchain. Companies need to balance among performance, privacy and risk as the blockchain will be growing continuously due to data agglomerations.

\subsubsection{Implementation decisions}

Integrated off-the-self blockchain solutions for supply chains are being developed and tested. However, depending on the blockchain implementation purpose, type of data and participants in the blockchain, enterprises can select the type of permission, consensus, smart contracts and storage location accordingly. In particular, for enterprises some data would be confidential, therefore a permissioned or hybrid blockchain would be more suitable to maintain firm proprietary competitive edge.

\section{Conclusions}

This research extends the "Principal Agent Theory" and the "Transaction Cost Analysis" Theory into the digital supply chain design domain, while contemporarily broadening the "Resource-Based View" Theory and the "Network Theory" view into the digital supply chain management field, specifically within the context of SDGs. In response to the research question considered in this study, blockchain-centric food supply chain designs that foster SDGs need to ensure data consistency for extending the focus on regulatory compliance purposes towards sustainability impact. To this end, the pivotal role of data capture is recognised to alleviate any data consistency challenges. In addition, blockchain-centric food supply chain management for SDGs needs to consider data interoperability among the dispersed systems and services to enable the efficient sharing of the content and context of the captured data. To that effect, the management of data archetypes is essential to link the different data sets that are available across multiple supply chain echelons. 
From a technical viewpoint, key primary and secondary research evidence suggests that data asymmetry exists in the Thai fish supply chain that hinders the achievement of SDGs. Especially, the requirements of a blockchain implementation should derive from: (i) the expected scope of the technology application; (ii) the nature and specificities of the targeted operations; (iii) the type of data to be gathered and shared; and (iv) the participants in the blockchain. Thereafter, organisations can consider the type of permission, consensus, smart contracts and storage locations accordingly. Furthermore, the study findings confirm that the application opportunities of blockchain in fish supply networks clearly indicate that a single technological solution to tackle supply chain transparency and traceability challenges is not feasible. The design of a respective supply network depends on the fundamentals of traceability systems, namely Key Data Elements and collection mechanisms thereof. These elements need to be designed and managed properly for enabling the benefits of blockchain. From an implementation perspective, in human-dependent data entry points, errors or even fraud incidents could occur; hence, Internet of Things applications can help address data inaccuracy issues. Except for the non-exclusive traceability, immutability and trust related benefits, blockchain enables sustainability performance and helps promote SDGs.

\subsection{Academic Contributions}

Within the particular context of SDGs, this research extends the "Principal Agent Theory" and the "Transaction Cost Analysis" Theory into the digital supply chain design domain. Cotemporally, the study findings extend the "Resource-Based View" Theory and the "Network Theory" view into the digital supply chain management field.

In the financial market, cautions about the prevalence of blockchain technology relate to the lack of governance as capital market regulators continue to raise disclosure requirements (Tappsocott and Tapscott, 2017b). However, in the case of food supply networks, operational 
and governance requirements are not significant thus fuelling the rapid and disruptive role of the technology, particularly in case blockchain is standardised and matures to accommodate considerable transaction volumes (Knezevic, 2018).

Notably, uncertainties around data structure and blockchain implementation result in only generic understanding over the issue and create confusion. On the contrary, this study contributes to the Operations Management field by applying a multiple case study approach, combining both primary and secondary data and information, to develop an integrated and pragmatic view over data structure and transparency in end-to-end fish supply networks enabled by blockchain technology that can result in an actual impact.

In addition, the findings of this research recognise the potential of blockchain to promote sustainability across a range of SDGs, depending on the particular operational context. In principal, blockchain promotes collaboration among stakeholders, hence allowing resources to be directed to priority areas. For the case of fish supply networks, blockchain could help remove from the food market environmentally damaging, illegal or unethical products of uncertain geographical origin and quality, whilst enhancing consumers' trust. Contemporarily, the increased transparency and accountability could stimulate business growth in local fish industries, subsequently contributing to the wellbeing of vulnerable populations. More specifically, this research articulates four principles for blockchain-centric supply chain design, along with a technology implementation framework, that could ultimately impact the resilience of the fishery system and the achievement of SDGs, namely:

- Principle \#1 "Data Archetypes" - Linking data sets available in multiple echelons of supply chains is essential.

- Principle \#2 "Data Capture" - Data on technology limitations needs to be captured.

- Principle \#3 "Data Consistency" - Data archetypes should not only be developed for compliance purposes, but they have to extend beyond regulatory requirements. 
- Principle \#4 "Data Interoperability" - Insignificant supply chain processes and operations have to be accounted.

In line with the research concerns identified by Kouhizadeh and Sarkis (2018), this research contributes to the blockchain body of research by investigating the real-world potential of blockchain implementation to support the competitiveness and export dynamics of the Thai fish industry. At a greater extent, blockchain could enable the holistic consideration of a supply chain to integrate all involved stakeholders, data and technologies thereof, in a collaborative style and promote environmental sustainability in a consistent manner (Koh et al., 2013).

\subsection{Management Implications}

The extant literature on blockchain technology is proliferated by conceptual expositions while real-word empirical cases in the non-finance sector are scarce (Ying et al., 2018). On the contrary, the findings of this research assist in addressing real-world practical issues by investigating fish supply chains in Thailand. The outcome of this research contributes to the management field by developing four principles for blockchain-centric supply chain design (i.e., "Data Archetypes" - "Data Capture" - "Data Consistency" -"Data Interoperability"), along with proposing a blockchain implementation framework structured around these principles, that could assist the decision-making process of managers towards the achievement of SDGs.

Blockchain in the fishing industry can enable the development of the necessary realtime supply network capabilities, e.g. visibility and data-enabled product quality reporting, to catapult network performance and competitiveness (Oliveira and Handfield, 2019). Our study reveals that the use of more sensors and automation inspires total quality management to include devices' certification and calibration into the blockchain. Moreover, contrary to 
established blockchain applications for cryptocurrency purposes, food supply networks entail physical commodities/products. Therefore, cryptographical proofs of the provenance and handling condition of fish could possibly disrupt the food certification industry as the cost of audits and certifications can be reduced.

\subsection{Limitations}

Few limitations that characterise this study occur that could motivate further research. Firstly, during the fieldwork few fishermen were seemed to be reluctant in providing direct answers about the fishing methods and records. As the Thailand's Fishery Foundation informed, such an attitude could be attributed to the abrupt changes in the legislation that did not allow enough time for the fishermen to adapt. Secondly, our research focused on the diversified data structures and recording practises while the provided blockchain-centric supply chain design and technology implementation framework does not capture technical details.

\subsection{Future Research}

In the future, we aim to perform a similar detailed study on the agricultural sector to support the dual objective of efficiency and sustainability, particularly with refer to natural and business resources' appropriation in sensitive regions (Leng et al., 2018). Regarding data privacy concerns, further research should also explore ownership and analytics functions that balance privacy preservation to information loss (Wieringa et al., 2019).

Finally, we aspire to conduct pertinent studies on multiple food products and industrial sectors such as automotive, aerospace and pharmaceuticals. Additionally, the proposed blockchain implementation framework requires multiple testing through action research in order to observe key patterns on how principles on blockchain-centric supply chain design and 
management vary in different sectors and how does product-process-location characteristics impact data consistency, data capture, data interoperability and data archetypes.

\section{Acknowledgements}

[The Acknowledgements are included in the 'Title_Page_(Revised)' file, uploaded separately, for ensuring anonymity].

\section{References}

Ahmed, S. and Broek N.T. (2017). Blockchain could boost food security. Nature, 550(7674), 43. doi: $10.1038 / 550043 \mathrm{e}$

Antonucci, F., Figorilli, S., Costa, C., Pallottino, F., Raso, L. and Menesatti, P. (2019). A review on blockchain applications in the agri-food sector. Journal of the Science of Food and Agriculture, 99(14), pp. 6129-6138. doi: 10.1002/jsfa.9912

Astill, J., Dara, R.A., Campbell, M., Farber, J.M., Fraser, E.D.G., Sharif, S. and Yada, R.Y. (2019). Transparency in food supply chains: A review of enabling technology solutions. Trends in Food Science and Technology, 91, pp. 240-247. doi: 10.1016/j.tifs.2019.07.024

Aung, M.M. and Chang, Y.S. (2014). Traceability in a food supply chain: Safety and quality perspectives. Food Control, 39(1), pp. 172-184. doi: 10.1016/j. foodcont.2013.11.007

Behnke, K. and Janssen, M.F.W.H.A. (2020). Boundary conditions for traceability in food supply chains using blockchain technology. International Journal of Information Management, 52, 101969. doi: 10.1016/j.ijinfomgt.2019.05.025 
Borrero, J.D. (2019). Agri-food supply chain traceability for fruit and vegetable cooperatives using Blockchain technology [Sistema de trazabilidad de la cadena de suministro agroalimentario para cooperativas de frutas y hortalizas basado en la tecnología Blockchain]. CIRIEC-Espana Revista de Economia Publica, Social y Cooperativa, 95, pp. 71-94. doi: 10.7203/CIRIEC-E.95.13123

Bumblauskas, D., Mann, A., Dugan, B. and Rittmer, J. (2020). A blockchain use case in food distribution: Do you know where your food has been? International Journal of Information Management, 52, 102008. doi: 10.1016/j.ijinfomgt.2019.09.004

Bush, S.R., Belton, B., Little, D.C. and Islam, M.S. (2019). Emerging trends in aquaculture value chain research." Aquaculture, 498, pp. 428-434. doi 10.1016/j.aquaculture.2018.08.077

Capgemini Research Institute (2018). Does blockchain hold the key to a new age of supply chain transparency and trust? Capgemini Research Institute, October 2018 Available at: https://www.capgemini.com/wp-content/uploads/2018/10/Digital-Blockchain-inSupply-Chain-Report.pdf (accessed: March 2020).

Chae, B., Yang, C., Olson, D. and Sheu, C. (2014). The impact of advanced analytics and data accuracy on operational performance: A contingent resource based theory (RBT) perspective. Decision Support Systems, 59, pp. 119-126. doi: 10.1016/j.dss.2013.10.012

Chapron, G. (2017). The environment needs cryptogovernance. Nature, 545(7655), pp. 403405. doi:10.1038/545403a

Chen, S., Liu, X., Yan, J., Hu, G. and Shi, Y. (2020). Processes, benefits, and challenges for adoption of blockchain technologies in food supply chains: A thematic analysis. Information Systems and e-Business Management, In Press. doi: 10.1007/s10257-020- 
00467-3

Choi, T.-M., Guo, S. and Luo, S. (2020). When blockchain meets social-media: Will the result benefit social media analytics for supply chain operations management? Transportation Research Part E: Logistics and Transportation Review, 135, 101860. doi: 10.1016/j.tre.2020.101860

Cook, B. (2018). Blockchain: Transforming the seafood supply chain. WWF, September 2018 Available at: http://awsassets.wwfnz.panda.org/downloads/draft_blockchain_report 1_ 4 1.pdf (accessed: March 2020).

Crew, S. (2018a). How blockchain can build trust in food. Food Manufacture, 2018 (May). ISSN: 00156477

Crew, S. (2018b). The potential of blockchain. Food Science and Technology, 32(1), pp. 5456. ISSN: 14753324

Dallasega, P. and Sarkis, J. (2018). Understanding greening supply chains: Proximity analysis can help. Resources, Conservation and Recycling, 139, pp. 76-77. doi: 10.1016/j.resconrec.2018.07.032

del Castillo, M. (2017). Intel demos seafood tracking on Sawtooth Lake blockchain. CoinDesk, April 2017. Available at: https://www.coindesk.com/intel-demos-seafood-trackingsawtooth-lake-blockchain/ (accessed: September 2018).

Department of Fishery (2018). Department of Fishery. Web: Department of Fishery. Available at: https://www4.fisheries.go.th/index.php/dof/main (accessed: August 2018).

Dolgui, A., Ivanov, D. and Sokolov, B. (2018). Ripple effect in the supply chain: An analysis 
and recent literature. International Journal of Production Research, 56(1-2), pp. 414430. doi: $10.1080 / 00207543.2017 .1387680$

dos Santos, R.B., Torrisi, N.M., Yamada, E.R.K. and Pantoni, R.P. (2019). IGR token-raw material and ingredient certification of recipe based foods using smart contracts. Informatics, 6(1), 11. doi: 10.3390/informatics6010011

Eisenhardt, K.M. (1989). Building theories from case study research. The Academy of Management Review, 14(4), pp. 532-550. doi: 10.2307/258557

European Commission (2015). EU acts on illegal fishing: Yellow card issued to Thailand while South Korea \& Philippines are cleared. European Commission, 2015. Available at: http://europa.eu/rapid/press-release_IP-15-4806_en.htm (accessed: October 2018).

FAO (2014). Best Practice Guidelines on Traceability. Food and Agriculture Organization of the United Nations: Bergen, Norway.

Feng, H., Wang, X., Duan, Y., Zhang, J. and Zhang, X. (2020). Applying blockchain technology to improve agri-food traceability: A review of development methods, benefits and challenges. Journal of Cleaner Production, 260, 121031. doi: 10.1016/j.jclepro.2020.121031

Fishcoin (2018). Fishcoin: A blockchain based data ecosystem for the global seafood industry. White Paper. Web: Fishcoin. Available at: https://fishcoin.co/files/fishcoin.pdf (accessed: September 2018).

Foster, S.J., Kuo, T.-C., Wan, A.K.Y. and Vincent, A.C.J. (2019). Global seahorse trade defies export bans under CITES action and national legislation. Marine Policy, 103, pp. 33-41. doi: 10.1016/j.marpol.2019.01.014 
Furlonger, R. and Valdes, R. (2017). Practical Blockchain: A Gartner Trend Insight Report. Stamford: Gartner. Available at: https://haas.campusgroups.com/htc/get_file?eid=139611897577441f06512fc062b0a63e (accessed: October 2018).

Galvez, J.F., Mejuto, J.C. and Simal-Gandara, J. (2018). Future challenges on the use of blockchain for food traceability analysis. TrAC Trends in Analytical Chemistry, 107, pp. 222-232. doi: 10.1016/j.trac.2018.08.011

Garner, H. (2018). 2017 Supply chain trends recap: Looking back at where we got to informs where we need to go now. Global Trade, January 2018. Available at: http://www.globaltrademag.com/features/2017-supply-chain-trends-recap (accessed: October 2018).

Gibbert, M., Ruigrok, W. and Wicki, B. (2008). What passes as a rigorous case study? Strategic Management Journal, 29(13), pp. 1465-1474. doi: 10.1002/smj.722

Girard, P. and Du Payrat, T. (2017). An inventory of new technologies in fisheries. Organisation for Economic Co-operation and Development, November 2017. Available at: https://www.oecd.org/greengrowth/GGSD 2017 Issue\%20Paper New\%20technologie s\%20in\%20Fisheries_WEB.pdf (accessed: October 2018).

Gopi, K., Mazumder, D., Sammut, J. and Saintilan, N. (2019). Determining the provenance and authenticity of seafood: A review of current methodologies. Trends in Food Science and Technology, 91, pp. 294-304. doi: 10.1016/j.tifs.2019.07.010

Halldórsson, Á. and Skjøtt-Larsen, T. (2004). Developing logistics competencies through third party logistics relationships. International Journal of Operations and Production Management, 24(2), pp. 192-206. doi: 10.1108/01443570410514885 
Halldórsson, Á., Kotzab, H., Mikkola, J. and Skjøtt-Larsen, T. (2007). Complementary theories to supply chain management. Supply Chain Management: An International Journal, 12(4), pp. 284-296. doi: 10.1108/13598540710759808

Howson, P. (2020). Building trust and equity in marine conservation and fisheries supply chain management with blockchain. Marine Policy, 115, 103873. doi: 10.1016/j.marpol.2020.103873

Hughes, L, Dwivedi, Y.K., Misra, S.K., Rana, N.P., Raghavan, V. and Akella, V. (2019). Blockchain research, practice and policy: Applications, benefits, limitations, emerging research themes and research agenda. International Journal of Information Management, 49, pp. 114-129. doi: 10.1016/j.ijinfomgt.2019.02.005

Irani, Z., Sharif, A.M., Lee, H., Aktas, E., Topaloğlu, Z., van't Wout, T. and Huda, S. (2018). Managing food security through food waste and loss: Small data to big data. Computers and Operations Research, 98, pp. 367-383. doi: 10.1016/j.cor.2017.10.007

Jensen, M.C. and Meckling, W.H. (1976). Theory of the firm: Managerial behavior, agency costs and ownership structure. Journal of Financial Economics, 3(4), pp. 305-360. doi: $10.1016 / 0304-405 X(76) 90026-X$

Johanson, J. and Mattsson, L.-G. (1987). Interorganizational relations in industrial systems: A network approach compared with the transaction-cost approach. International Studies of Management and Organization, 17(1), pp. 34-48. doi: $10.1080 / 00208825.1987 .11656444$

Juskalian, R. (2018). The place where life hangs by a chain. MIT Technology Review, 121(3), pp. 42-51. ISSN: 1099274X

Kamble, S.S., Gunasekaran, A. and Arha, H. (2019a). Understanding the blockchain 
technology adoption in supply chains-Indian context. International Journal of Production Research, 57(7), pp. 2009-2033. doi: 10.1080/00207543.2018.1518610

Kamble, S.S., Gunasekaran, A. and Sharma, R. (2019b). Modeling the blockchain enabled traceability in agriculture supply chain. International Journal of Information Management, In Press. doi: 10.1016/j.ijinfomgt.2019.05.023

Kamble, S.S, Gunasekaran, A. and Gawankar, S.A. (2020). Achieving sustainable performance in a data-driven agriculture supply chain: A review for research and applications. International Journal of Production Economics, 219, pp. 179-194. doi: 10.1016/j.ijpe.2019.05.022

Kamilaris, A., Fonts, A. and Prenafeta-Boldv́, F.X. (2019). The rise of blockchain technology in agriculture and food supply chains. Trends in Food Science and Technology, 91, pp. 640-652. doi: 10.1016/j.tifs.2019.07.034

Karlsen, K.M., Dreyer, B., Olsen, P. and Elvevoll, E.O. (2013). Literature review: Does a common theoretical framework to implement food traceability exist? Food Control, 32(2), pp. 409-417. doi: 10.1016/j.foodcont.2012.12.011

Kayikci, Yasanur, et al. (2020) "Food supply chain in the era of Industry 4.0: Blockchain technology implementation opportunities and impediments from the perspective of people, process, performance and technology." Production Planning and Control

Kim, H.M. and Laskowski, M. (2018). Toward an ontology-driven blockchain design for supply-chain provenance. Intelligent Systems in Accounting, Finance and Management, 25(1), pp. 18-27. doi: 10.1002/isaf.1424

Kittipanya-ngam, P. and Tan, K.H. (2020). A framework for food supply chain digitalization: Lessons from Thailand. Production Planning and Control, 31(2-3), pp. 158-172. doi: 
Klasen, S., Lechtenfeld, T. and Povel, F. (2015). A feminization of vulnerability? Female headship, poverty, and vulnerability in Thailand and Vietnam. World Development, 71, pp. 36-53. doi: 10.1016/j.worlddev.2013.11.003

Knezevic, D. (2018). Impact of blockchain technology platform in changing the financial sector and other industries. Montenegrin Journal of Economics, 14(1), pp. 109-120. doi: $10.14254 / 1800-5845 / 2018.14-1.8$

Koh, S.C.L., Genovese, A., Acquaye, A.A., Barratt, P., Rana, N., Kuylenstierna, J. and Gibbs, D. (2013). Decarbonising product supply chains: Design and development of an integrated evidence-based decision support system - The supply chain environmental analysis tool (SCEnAT). International Journal of Production Research, 51(7), pp. 20922109. doi: $10.1080 / 00207543.2012 .705042$

Kohtamäki, M., Parida, V., Oghazi, P., Gebauer, H. and Baines, T. (2019). Digital servitization business models in ecosystems: A theory of the firm. Journal of Business Research, 104, pp. 380-392. doi: 10.1016/j.jbusres.2019.06.027

Konovalenko, I. and Ludwig, A. (2019). Event processing in supply chain management - The status quo and research outlook. Computers in Industry, 105, pp. 229-249. doi: 10.1016/j.compind.2018.12.009

Kouhizadeh, M. and Sarkis, J. (2018). Blockchain practices, potentials, and perspectives in greening supply chains. Sustainability, 10(10), 3652. doi: 10.3390/su10103652

Kshetri, N. (2018). Blockchain's roles in meeting key supply chain management objectives. International Journal of Information Management, 39, pp. 80-89. doi: 
10.1016/j.ijinfomgt.2017.12.005

Kumar, A., Liu, R. and Shan, Z. (2019). Is blockchain a silver bullet for supply chain management? Technical challenges and research opportunities. Decision Sciences. doi:10.1111/deci.12396

Kumar, A., Liu, R. and Shan, Z. (2020). Is blockchain a silver bullet for supply chain management? Technical challenges and research opportunities. Decision Sciences, 51(1), pp. 8-37. doi: 10.1111/deci.12396

Kuo, T.-C., Laksanawimol, P., Aylesworth, L., Foster, S.J. and Vincent, A.C.J. (2018). Changes in the trade of bycatch species corresponding to CITES regulations: The case of dried seahorse trade in Thailand. Biodiversity and Conservation, 27(13), pp. 34473468. doi: 10.1007/s10531-018-1610-2

Leng, K., Bi, Y., Jing, L., Fu, H.-C. and Van Nieuwenhuyse, I. (2018). Research on agricultural supply chain system with double chain architecture based on blockchain technology. Future Generation Computer Systems, 86, pp. 641-649. doi: 10.1016/j.future.2018.04.061

Lezoche, M., Panetto, H., Kacprzyk, J., Hernandez, J.E. and Alemany Díaz, M.M.E. (2020). Agri-food 4.0: A survey of the supply chains and technologies for the future agriculture. Computers in Industry, 117, 103187. doi: 10.1016/j.compind.2020.103187

Lin, C., He, D., Huang, X., Choo, K.-K.R. and Vasilakos, A.V. (2018). BSeIn: A blockchainbased secure mutual authentication with fine-grained access control system for industry 4.0. Journal of Network and Computer Applications, 116, pp. 42-52. doi: 10.1016/j.jnca.2018.05.005 
Lin, Y.-P., Petway, J. R., Anthony, J., Mukhtar, H., Liao, S.-W., Chou, C.-F. and Ho, Y.-F. (2017). Blockchain: The evolutionary next step for ICT e-agriculture. Environments, 4(3), 50. doi: 10.3390/environments4030050

Lindley, J. and Techera, E.J. (2017). Overcoming complexity in illegal, unregulated and unreported fishing to achieve effective regulatory pluralism. Marine Policy, 81, pp. 7179. doi: 10.1016/j.marpol.2017.03.010

Loh, T.-L., Tewfik, A., Aylesworth, L. and Phoonsawat, R. (2016). Species in wildlife trade: Socio-economic factors influence seahorse relative abundance in Thailand. Biological Conservation, 201, pp. 301-308. doi: 10.1016/j.biocon.2016.07.022

Mai, N., Bogason, S.G., Arason, S., Árnason, S.V., and Matthíasson, T.G. (2010). Benefits of traceability in fish supply chains - Case studies. British Food Journal, 112(9), pp. 9761002. doi: $10.1108 / 00070701011074354$

Mai, N.T.T., Margeirsson, S., Stefansson, G. and Arason, S. (2010). Evaluation of a seafood firm traceability system based on process mapping information: More efficient use of recorded data. Journal of Food, Agriculture and Environment, 8(2), pp. 51-59.

Marfia, G. and Degli Esposti, P. (2017). Blockchain and sensor-based reputation enforcement for the support of the reshoring of business activities. In: A.Vecchi (Eds.), Reshoring of Manufacturing. Measuring Operations Performance (pp. 125-139). Springer, Cham.

McCutcheon, D.M. and Meredith, J.R. (1993). Conducting case study research in operations management. Journal of Operations Management, 11(3), pp. 239-256. doi: $10.1016 / 0272-6963(93) 90002-7$

Min, H. (2019). Blockchain technology for enhancing supply chain resilience. Business 
Horizons, 62(1), pp. 35-45. doi: 10.1016/j.bushor.2018.08.012

Mondal, S., Wijewardena, K.P., Karuppuswami, S., Kriti, N., Kumar, D. and Chahal, P. (2019). Blockchain inspired RFID-based information architecture for food supply chain. IEEE Internet of Things Journal, 6(3), pp. 5803-5813. doi: 10.1109/JIOT.2019.2907658

Muzammal, M., Qu, Q. and Nasrulin, B. (2019). Renovating blockchain with distributed databases: An open source system. Future Generation Computer Systems, 90, pp. 105117. doi: 10.1016/j.future.2018.07.042

Nash, K.S. (2018). Walmart-led blockchain effort seeks farm-to-grocery-aisle view of food supply chain. The Wall Street Journal, June 2018. Available at: https://blogs.wsj.com/cio/2018/06/25/walmart-led-blockchain-effort-seeks-farm-togrocery-aisle-view-of-food-supply-chain/ (accessed: September 2018).

Ndraha, N., Hsiao, H.-I, Vlajic, J., Yang, M.-F. and Lin, H.-T.V. (2018). Time-temperature abuse in the food cold chain: Review of issues, challenges, and recommendations. Food Control, 89, pp. 12-21. doi: 10.1016/j.foodcont.2018.01.027

Nidumolu, R., Ellison, J., Whalen, J. and Billman, E. (2014). The collaboration imperative. Harvard Business Review, 92(4), pp. 76-84.

Nong, D. (2019). Potential economic impacts of global wild catch fishery decline in Southeast Asia and South America. Economic Analysis and Policy, 62, pp. 213-226. doi: 10.1016/j.eap.2019.04.004

Oliveira, M.P.V. de and Handfield, R. (2019). Analytical foundations for development of realtime supply chain capabilities. International Journal of Production Research, 57(5), pp. 1571-1589. doi: 10.1080/00207543.2018.1493240 
Pendrous, R. (2017). Blockchain takes off in food and drink. Food Manufacture, 2017 (October). ISSN: 00156477

Perry, A.L., Lunn, K.E. and Vincent, A.C.J. (2010). Fisheries, large-scale trade, and conservation of seahorses in Malaysia and Thailand. Aquatic Conservation: Marine and Freshwater Ecosystems, 20(4), pp. 464-475. doi: 10.1002/aqc.1112

Poseidon (2019). The illegal, unreported ad unregulated fishing index. The Global Initiative Against Transnational Organised Crimes, January 2019 Available at: https://globalinitiative.net/wp-content/uploads/2019/02/IUU-Fishing-Index-Reportweb-version.pdf (accessed: March 2020).

Provenance (2016). From shore to plate: Tracking tuna on blockchain. Provenance, July 2016. Available at: https://www.provenance.org/tracking-tuna-on-the-blockchain\#blockchains (accessed: September 2018).

Raut, R.D., Mangla, S.K., Narwane, V.S., Gardas, B.B., Priyadarshinee, P. and Narkhede, B.E. (2019). Linking big data analytics and operational sustainability practices for sustainable business management. Journal of Cleaner Production, 224, pp. 10-24. doi: 10.1016/j.jclepro.2019.03.181

Rindfleisch, A and Heide, J.B. (1997). Transaction cost analysis: Past, present, and future applications. Journal of Marketing, 61(4), pp. 30-54. doi: 10.2307/1252085

Rinehart, L.M., Eckert, J.A., Handfield, R.B., Page, T.J. and Atkin, T. (2004). An assessment of supplier-customer relationships. Journal of Business Logistics, 25(1), pp. 25-62. doi: 10.1002/j.2158-1592.2004.tb00169.x

Saberi, S., Kouhizadeh, M., Sarkis, J. and Shen, L. (2019). Blockchain technology and its relationships to sustainable supply chain management. International Journal of 
Production Research, 57(7), pp. 2117-2135. doi: 10.1080/00207543.2018.1533261

Sander, F., Semeijn, J. and Mahr, D. (2018). The acceptance of blockchain technology in meat traceability and transparency. British Food Journal, 120(9), pp. 2066-2079. doi: 10.1108/BFJ-07-2017-0365

Sasipornkarn, E. (2019). Thai fishing industry makes headway, but challenges remain. Deutsche Welle, November 2019 Available at: https://p.dw.com/p/3SvXf (accessed: March 2020).

Saunders, M.N.K., Lewis, P. and Thornhill, A. (2009). Research methods for business students ( $5^{\text {th }}$ ed.). Prentice Hall: New York, USA.

Sener, A., Barut, M., Oztekin, A., Avcilar, M.Y. and Yildirim, M.B. (2019). The role of information usage in a retail supply chain: A causal data mining and analytical modeling approach. Journal of Business Research, 99, pp. 87-104. doi: 10.1016/j.jbusres.2019.01.070

Suichies, B. (2015). Why blockchain must die in 2016. Medium, December 2015 Available at: https://medium.com/block-chain/why-blockchain-must-die-in-2016-e992774c03b4 (accessed: March 2020).

Tanielian, A. (2018). Sustainability and competitiveness in Thai rubber industries. Copenhagen Journal of Asian Studies, 36(1), pp. 50-78.

Tappsocott, D. and Tapscott, A. (2017). Realizing the Potential of Blockchain: A Multistakeholder Approach to the Stewardship of Blockchain and Cryptocurrencies. World Economic Forum. Cologny/Geneva: World Economic Forum.

Tian, F. (2017). A supply chain traceability system for food safety based on HACCP, 
blockchain \& Internet of things. International Conference on Service Systems and Service Management, Dalian, pp. 1-6. doi: 10.1109/ICSSSM.2017.7996119

Tiwari, S., Wee, H.M. and Daryanto, Y. (2018). Big data analytics in supply chain management between 2010 and 2016: Insights to industries. Computers and Industrial Engineering, 115, pp. 319-330. doi: 10.1016/j.cie.2017.11.017

Tranfield, D., Denyer, D. and Smart, P. (2003). Towards a methodology for developing evidence-informed management knowledge by means of systematic review. British Journal of Management, 14(3), pp. 207-222. doi: 10.1111/1467-8551.00375

Treiblmaier, H. (2018). The impact of the blockchain on the supply chain: A theory-based research framework and a call for action. Supply Chain Management: An International Journal, 23(6), pp. 545-559. doi: 10.1108/SCM-01-2018-0029

Trkman, P., Štemberger, M.I., Jaklič, J. and Groznik, A. (2007). Process approach to supply chain integration. Supply Chain Management, 12(2), pp. 116-128. doi: $10.1108 / 13598540710737307$

USDA (2018). Seafood Report: Thailand. Bangkok: United States Department of Agriculture Foreign Agricultural Service, Global Agricultural Information Network.

van Ruth, S.M., Luning, P.A., Silvis, I.C.J., Yang, Y. and Huisman, W. (2018). Differences in fraud vulnerability in various food supply chains and their tiers. Food Control, 84, pp. 375-381. doi: 10.1016/j.foodcont.2017.08.020

Visser, C. and Hanich, Q. (2018). How blockchain is strengthening tuna traceability to combat illegal fishing. University of Wollongong, January 2018 Available at: https://ro.uow.edu.au/cgi/viewcontent.cgi?article=4374\&context=1hapapers $\quad$ (accessed: 
March 2020).

Viswanathan, P. (2008). Emerging smallholder rubber farming systems in India and Thailand: A comparative economic analysis. Asian Journal of Agriculture and Development, 5(2), pp. 1-20. doi: 10.22004/ag.econ.198984

Wacker, J.G., Yang, C. and Sheu, C. (2016). A transaction cost economics model for estimating performance effectiveness of relational and contractual governance: Theory and statistical results. International Journal of Operations and Production Management, 36(11), pp. 1551-1575. doi: 10.1108/IJOPM-10-2013-0470

Whipple, J. and Roh, J. (2010). Agency theory and quality fade in buyer-supplier relationships. International Journal of Logistics Management, 21(3), pp. 338-352. doi: $10.1108 / 09574091011089781$

Wieringa, J., Kannan, P.K., Ma, X., Reutterer, T., Risselada, H. and Skiera, B. (2019). Data analytics in a privacy-concerned world. Journal of Business Research, In Press. doi: 10.1016/j.jbusres.2019.05.005

Wipatayotin, A. (2019). IUU fishing is a crime issue, says Prawit. Bangkok Post, January 2019 Available at: https:/globalinitiative.net/wp-content/uploads/2019/02/IUU-FishingIndex-Report-web-version.pdf (accessed: March 2020).

WWF (2018). New blockchain project has potential to revolutionise seafood industry. WWF, January 2018 Available at: https://www.wwf.org.nz/media_centre/news/?15541/NewBlockchain-Project-has-Potential-to-Revolutionise-Seafood-Industry $\quad$ (accessed: September 2018).

Xiong, X., D’Amico, P., Guardone, L., Castigliego, L., Guidi, A., Gianfaldoni, D. and Armani, 
A. (2016). The uncertainty of seafood labeling in China: A case study on Cod, Salmon and Tuna. Marine Policy, 68, pp. 123-135. doi: 10.1016/j.marpol.2016.02.024

Yin, R.K. (2003). Case Study Research: Design and Methods (3rd edition). SAGE Publications, Thousand Oaks, California.

Yin, R.K. (2009). Case Study Research: Design and Methods (4th edition). SAGE Publications, Thousand Oaks, California.

Ying, W., Jia, S. and Du, W. (2018). Digital enablement of blockchain: Evidence from HNA group. International Journal of Information Management, 39, pp. 1-4. doi: 10.1016/j.ijinfomgt.2017.10.004

Zhao, G., Liu, S. Lopez, C., Lu, H., Elgueta, S., Chen, H. and Boshkoska, B.M. (2019). Blockchain technology in agri-food value chain management: A synthesis of applications, challenges and future research directions. Computers in Industry, 109, pp. 83-99. doi: 10.1016/j.compind.2019.04.002 


\section{Appendix}

[Table A1 about here]

Table A1. Interviews' salient points.

[Table A2 about here]

Table A2. Key Data Elements recorded during commercial fishing operations.

[Table A3 about here]

Table A3. Key Data Elements recorded by the canned tuna manufacturer at the different supply chain echelons. 